\title{
PENGARUH SUPERVISI KEPALA SEKOLAH DAN PENGEMBANGAN TENAGA PENDIDIK TERHADAP KINERJA GURU MADRASAH ALIYAH SWASTA DI KABUPATEN LIMA PULUH KOTA
}

\author{
Ahmad Maulid \\ Kepala Madrasah Aliyah Ma'arif As-Sa'adiyah Payakumbuh \\ e-mail: amd.maulid@gmail.com
}

\begin{abstract}
This quantitative research of causal design was aimed at testing the effect of principal's supervision towards teachers' performance of Madrasah Aliyah Swasta in Lima Puluh Kota. The population were 172 teachers. The sample were taken by using Sloviv formula. The data were collected by using questionnaire Likert scale. The data were analyzed by using double linear regresion, $F_{\text {test }}, t_{\text {test }}$ dan $R_{\text {test }}$. The results obtained indicate that 1$)$ there was positive significant effect of principal's supervision towards teachers' performance; 2) no significant effect of teachers' professional development towards teachers' performance; 3) the principal's supervision and teachers' professional development gave significant effect towards teachers' performance (sig) < 0,05. Based on the coeficient analysis, the principal's supervision and teachers' professional development gave effect $17.8 \%$ towards teachers' performance of Madrasah Aliyah Swasta in Lima Puluh Kota and 82,2\% from another variable which was not discussed in this research.
\end{abstract}

Keywords: Principal's Supervision, Teachers' Professional Development, Teachers' Performance, Madrasah Aliyah Swasta, Lima Puluh Kota.

\section{PENDAHULUAN}

Lembaga pendidikan Madrasah Aliyah Swasta (MAS) adalah salah satu lembaga yang berperan penting dalam menyiapkan sumber daya manusia yang cerdas dan komprehensif dimasa yang akan datang. Untuk menyipakan hal tersebut diperlukan guru yang profesional dan berpotensi tinggi. Fattah (2000: 1) mengemukakan bahwa kualitas guru merupakan salah satu kunci utama keberhasilan dalam pendidikan. Kualitas guru ditentukan oleh faktor-faktor seperti wawasan, latar belakang pendidikan dan kompetensi.
Kinerja guru berkaitan dengan kemampuan yang dimiliki guru dalam menjalankan tugasnya. Sukoco \& Kunartinah (2010: 75) menyimpulkan bahwa kemampuan guru dalam mengelola proses pembelajaran tercermin pada kualitas guru dalam menjalankan tugas dan fungsinya sebagai pendidik dan pengajar. Untuk meningkatkan kinerja guru perlu pembinaan dari kepala sekolah melaui kegiatan supervisi. Supardi (2014: 9) juga menyatakan bahwa "Salah satu faktor yang mempengaruhi kinerja guru adalah pembinaan oleh kepala sekolah melalui supervisi”. Sejalan dengan pendapat Mulyasa (2012: 5) bahwa, sukses tidaknya pendidikan 
dan pembelajaran di sekolah salah satunya dipengaruhi oleh kemampuan kepala sekolah dalam mengelola setiap komponen sekolah (who is behind the school). Pengembangan kemampuan guru MAS tidak hanya melalui supervsi kepala sekolah tetapi juga melalui pendidikan, pelatihan, workshop, seminar, Kelompok Kerja Guru (KKG).

Di Kabupaten Lima Puluh Kota menurut data ditemukan beberapa permasalahan di antaraanya; 1) belum semua guru berlatar belakang pendidikan SI, 2) belum semua guru mampu membuat perencanaan pembelajaran, 3 hasil kinerja guru masih berada pada kategori cukup, 4) kepala sekolah belum melaksanakn supervisi secara maksimal, 5) kegiatan pendidkan pelatihan belum merata untuk semua guru, 6) belum semua guru berstatus PNS. Tujuan dalam penelitian ini adalah mengungkap 1) apakah supervisi kepala sekolah berpengaruh terhadap kinerja guru MAs di Lima Puluh Kota; 2) apakah pengembangan tenaga pendidik berpengaruh terhadap kinerja guru MAS di Lima Puluh Kota; dan (3) apakah supervisi kepala sekolah dan pengembangan tenaga pendidik berpengaruh terhadap kinerja guru MAS di Lima Puluh Kota.

\section{KAJIAN TEORI}

Salah satu keberhasilan pendidikan taman kanak-kanak dipengaruhi oleh kinerja guru (job performance). Menurut Supardi (2014:47) bahwa kinerja merupakan hasil kerja yang telah dicapai oleh seseorang berdasarkan standarisasi dan waktu yang disesuaikan dengan jenis pekerjaan berdasarkan norma dan etika yang telah ditetapkan oleh organisasi.

Lebih jauh Supardi (2014: 20-21) mengemukakan bahwa kinerja guru adalah kemampuan dan keberhasilan guru dalam melaksanakan tugas-tugas pembelajaran yang ditunjukkan oleh dimensi 1) kemampuan menyusun rencana pembelajaran dengan indikator: (a) merencanakan pengelolaan pembelajaran, (b) merencanakan pengorganisasian bahan pelajaran, (c) merencanakan pengelolaan kelas, dan (d) merencanakan penilaian hasil belajar; 2) dimensi kemampuan melaksanakan pembelajaran dengan indikator: (a) memulai pemebelajaran, (b) meneglola pembelajaran, (c) mengorganisasikan pembelajaran, (c) melaksanakan penilaian proses dan hasil belajar, (d) mengakhiri pembelajaran; 3) dimensi kemapuan melaksanakan hubungan antar pribadi dengan indikator: (a) mengembangkan sikap positif peserta didik, (b) menampilkan kegairahan dalam pembelajaran, (c) mengelola interaksi perilaku dalam kelas; 4) dimensi kemapuan melaksanakn penilaian hasil belajar dengan indikator, (a) merencanakan penilaian, (b) 
melaksanakan penilaian, (c) mengelola dan memeriksa hasil penilaian, (d) memanfaatkan hasil penilaian, (e) melaporkan hasil penilaian; 5) dimensi kemampuan melaksanakan program pengayaan dengan indikator: (a) memberikan tugas, (b) memberikan bahan bacaan, (c) tugas membantu guru; dan 6) dimensi kemmapuan melaksanakan program ramedial dengan indikator: (a) memberikan bimbingan khusus, (b) penyederhanaan.

Wibowo (2011: 4-5) berpendapat bahwa pengukuran kinerja dilakukan untuk mengetahui apakah terdapat deviasi antara proses yang direncanakan dengan kenyataan. Menurut Iswanto (2012: 5-20) ada tiga pilihan dari kinerja yang akan dinilai, yaitu: fokus penilaian, aspek yang dinilai, dan jangkar level kinerja.

Daft (2003: 170) mengemukakan gagasannya bahwa penilaian kinerja bukan merupakan sesuatu yang dilakukan setahun sekali tetapi harus dilakukan secara terus menerus, sebagai bagian dari pertimbangan kenaikan pembayaran. Lebih lanjut Daft (2003: 172) menyatakan bahwa apabila kinerja akan dinilai dengan akurat, sistem penilaian diharuskan untuk menilai setiap dimensi kinerja yang relevan.

Menurut Rahadhini dan Sugiono (2011: 1) faktor internal yang mempengaruhi kinerja guru antara lain motivasi kerja, pengetahuan tugas pekerjaan dan kreatifitas, sedangkan faktor eksternal antara lain kepemimpinan, kompensasi, komunikasi dan lingkungan kerja. Mulyasa (2009: 100) mengemukakan bahwa upaya untuk meningkatkan kinerja guru antara lain; 1) mengikutsertakan guru-guru dalam penataran, untuk menambah wawasan para guru; 2) Kepala Sekolah harus berusaha menggerakkan tim evaluasi hasil belajar peserta didik untuk lebih giat bekerja, kemudian hasilnya diumumkan secara terbuka dan di perlihatkan di papan pengumuman; dan 3) menggunakan waktu belajar secara efektif di sekolah, dengan cara mendorong para guru untuk memulai dan mengakhiri pembelajaran sesuai waktu yang telah ditentukan, serta memanfaatkannya secara efektif dan efisien untuk kepentingan pembelajaran.

Permendiknas no 13 tahun 2007 tentang standar Kepala Sekolah, bahwa salah satu kompetensi yang harus dimiliki seorang kepala sekolah adalah kompetensi supervisi, Purwanto (2002: 76). Selain itu Sahertian (2010: 19) juga menyatakan bahwa supervisi tidak lain dari usaha memberi layanan kepada guru-guru baik secara indiviual maupun secara kelompok dalam usaha memperbaiki pengajaran. Supardi (2014: 76) menyatakan bahwa supervisi adalah suatu pelayanan (service) untuk membantu, 
mendorong, membimbing, dan membina, guru-guru agar mampu meningkatkan kemampuan dan keterampilan dalam menjalankan tugas pembelajaran, dan Mulyasa (2012: 181) bahwa kepala sekolah harus mampu menjadi supervisor tim dengan melibatkan guru, staf, dan siswa dalam mewujudkan proses belajar mengajar yang efektif dan efisien sehingga tercapai produktivitas belajar untuk meningkatkan mutu pendidikan.

Supardi (2014: 81) menjelaskan tujuan supervisi secara khusus yaitu 1) membantu guru untuk memahami dengan jelas tujuan pendidikan ynag hendak dicapai; 2) membantu guru dalam mempersiapkan bahan peajaran yang akan disajikan kepada peserta didik; 3) membantu guru dalam menggunakan sumber pengalaman pembelajaran; 4) membantu guru dalam menilai hasil yang telah dicapai peserta didik; dan 5) menambah kegairahan guruguru untuk meningkatkan mutu kerjanya dengan memberikan berbagai penegetahuan sehubungan dengan jabatannya. Agar supervisi tersebut dapat dilakukan dengan baik. Menurut Sahertian (2010: 20) prinsip dasar yang harus dilaksanakan dalam supervisi adalah 1) prinsip ilmiah (scientific); 2) prinsip demokratis; 3) prinsip kerja sama, memberi support mendorong dan menstimulasi guru; dan 4) prinsip konstruktif dan kreatif. Indikator supervisi menurut Glickman (1998: 146) yang dikutip Supardi (2014: 90) yaitu 1) pengembangan kurikulum; 2) observasi; dan 3) pengembangan profesionalisme guru.

Dunia pendidikan mengalami perubahan baik itu dari segi kurikulum, sistem dan model pembelajaran yang sudah dianggap usang. Dalam upaya meningkatkan mutu dan kualitas pendidikan setiap lembaga pendidikan dirasa perlu mengembangkan manajemen, khusunya pengembangan sumber daya guru atau tenaga pendidik. Gaol (2015: 231) menyatakan bahwa pegawai yang telah usang belum tentu karena usia, oleh karena itu penanggulangan pegawai yang usang pengetahuan atau kempuannya adalah dengan pensiun. Gejala-gejala keusangan adalah 1) sikap tidak pantas; 2) unjuk kerja yang rendah, sering melakukan kesalahan; 3) prosedur kerja yang dipakai sudah kuno. Rahadhini \& Sugiono (2011) mengemukakan bahwa untuk menjadi guru yang profesional perlu pembinaan berkelanjutan dengan cara memberikan pendidikan dan pelatihan, KKG, memberi motivasi terhadap guru yang belum mempunyai ijazah S1 yang relevan, serta selalu memberi motivasi tehadap guru agar terampil dan profesional di bidangnya sehingga peningkatan kinerja guru dapat terwujud dengan baik. 


\section{METODE PENELITIAN}

Penelitian ini adalah penelitian kuantitatif dengan desain kautsal, populasi penelitian terdiri dari 10 MAS di Lima Puluh Kota yang jumlah gurunya 172 orang dan besaran sampel 63 orang ditentukan dengan menggunakan rumus Sloviv, dan pengambilan sampel menggunakan teknik Ramdam Sampling. Data penelitian ini dikumpulkan dengan angket menggunakan model skala Likert. Kemudian analisis data dilakukan dengan SPSS.

\section{HASIL PENELITIAN DAN PEMBAHASAN}

Tabel 1. Karateristik Responden

\begin{tabular}{cccc}
\hline Karateristik & Jenis Karakteristik & Frekuensi & Persentase \\
\hline Jenis kelamin & Laki laki & 10 & $15,9 \%$ \\
& Perempuan & 53 & $84,1 \%$ \\
Usia & $20-25$ tahun & 4 & $6,3 \%$ \\
& $26-36$ tahun & 11 & $17,5 \%$ \\
& $36-45$ tahun & 26 & 44,35 \\
Tingkat & $>45$ tahun & 22 & $34,9 \%$ \\
pendidikan & Non S1 & 17 & $1,6 \%$ \\
& SI & 31 & $93,7 \%$ \\
Masa kerja & S2 & 15 & $4,8 \%$ \\
& $\leq 5$ tahun & 17 & $27,0 \%$ \\
& $6-10$ tahun & 31 & $49,2 \%$ \\
Jenis Pegawai & $\geq 10$ tahun & 15 & $23,8 \%$ \\
& PNS & 13 & $20,6 \%$ \\
& NON PNS & 50 & $79,4 \%$ \\
\hline
\end{tabular}

Tingkat capaian dan kecenderungan jawaban responden tersebut dapat dilihat dari bentuk statistik deskriptif dari masingmasing variabel. Jawaban responden ditunjukkan dengan katergori nilai rata-rata jawaban, di mana jawaban masing-masing variabel tersebut dapat digambarkan dari data masing-masing variabel di bawah ini.

1. Variabel Kinerja Guru (Y)

Tabel 2. Tingkat Pencapaian Respon Untuk Setiap Indikator Kinerja Guru (Y)

\begin{tabular}{|c|c|c|c|c|c|}
\hline No & Indikator & $\begin{array}{l}\text { Skor } \\
\text { Ideal }\end{array}$ & $\begin{array}{c}\text { Skor } \\
\text { Rata-Rata }\end{array}$ & $\begin{array}{c}\% \\
\text { capaian }\end{array}$ & Kategori \\
\hline 1 & Perencanaan pembelajaran & 40 & 32,31 & 80,08 & Baik \\
\hline 2 & Pelaksanaan pembelajaran & 60 & 49,61 & 82,66 & Baik \\
\hline 3 & $\begin{array}{l}\text { Membina hubungan, } \\
\text { membimbing, melatih dan } \\
\text { pengasuhan }\end{array}$ & 35 & 28,59 & 81,65 & Baik \\
\hline 4 & $\begin{array}{l}\text { Pelaksanaan Penilaian } \\
\text { (analisis dan perbaikan } \\
\text { pengayaan) }\end{array}$ & 30 & 24,17 & 80,56 & Baik \\
\hline
\end{tabular}




$\begin{array}{lllll}\text { Keseluruhan respon kinerja } & 165 & 134,68 & 81,62 & \text { Baik }\end{array}$
guru

Berdasarkan data pada Tabel tersebut secara umum tingkat pencapaian rata-rata jawaban responden adalah $81,6 \%$ atau dikategorikan baik. Artinya secara umum dapat dikatakan bahwa kinerja guru MAs di Lima Puluh Kota tahun 2016 adalah baik.

2. Variabel Supervisi Kepala Sekolah

\begin{tabular}{clcccc} 
Tabel 3. Tingkat Capaian Respon untuk Indikator Supervisi Kepala Sekolah & (X1) \\
\cline { 1 - 5 } No & \multicolumn{1}{c}{ Indikator } & $\begin{array}{c}\text { Skor } \\
\text { Ideal }\end{array}$ & $\begin{array}{c}\text { Skor } \\
\text { Rata-Rata }\end{array}$ & \% Capaian & Kategori \\
\hline 1 & $\begin{array}{l}\text { Pengembangan } \\
\text { kurikulum }\end{array}$ & 40 & 32,95 & 82,37 & Baik \\
2 & Observasi & 70 & 55,18 & 78,82 & $\begin{array}{c}\text { Cukup Baik } \\
\text { Baik }\end{array}$ \\
3 & $\begin{array}{l}\text { Pengembangan } \\
\text { profesi }\end{array}$ & 30 & 24,55 & 81,83 & Baik \\
$\begin{array}{l}\text { Keseluruhan Respon } \\
\text { Supervisi Kepala } \\
\text { Sekolah }\end{array}$ & 140 & 122,7 & 80,5 & \\
\hline
\end{tabular}

Secara umum tingkat pencapaian ratarata jawaban responden adalah $80,5 \%$, ratarata ini dikategorikan ke dalam kategori baik, artinya secara umum dapat dikatakan bahwa supervisi kepala MAS Lima Puluh Kota dalam kategori baik.

3. Variabel Pengembangan Tenaga Pendidik

Tabel 3. Tingkat Capaian Respon pada Indikator Pengembangan Tenaga Pendidik

\begin{tabular}{llcccc}
\hline No & \multicolumn{1}{c}{ Indikator } & $\begin{array}{c}\text { Skor Ideal } \\
\text { Skor Rata- } \\
\text { Rata }\end{array}$ & \% Capaian & Kategori \\
\hline 1 & $\begin{array}{l}\text { Pendidikan dan } \\
\text { pelatihan }\end{array}$ & 35 & 25.96 & 74.17 & Cukup \\
2 & 30 & 21,81 & 73 & Cukup \\
$\begin{array}{l}\text { WorkShop dan } \\
\text { Seminar }\end{array}$ & 25 & 18,7 & 62.3 & Cukup \\
$\quad \begin{array}{l}\text { Kegiatan KKG di } \\
\text { gugus }\end{array}$ & 90 & 66,48 & 69.82 & Cukup \\
$\begin{array}{l}\text { Rata-Rata } \\
\text { Pengembangan Tenaga } \\
\text { Pendidik }\end{array}$ & & & & \\
\hline
\end{tabular}

Secara umum ditampilkan bahwa jumlah skor rata-rata adalah 66,48 dari 90 skor ideal, dari skor ini hasil tingkat pencapaian jawaban responden berjumlah
69,82\%. Rata-rata ini dikategorikan pada kategori cukup.

Dalam penelitian ini pengujian dilakukan dengan menggunakan SPSS, di 
mana suatu variabel dapat dikatakan reliable jika memberikan nilai Cronbach Alpha (a) >
0,6. Uji reliabilitas dapat dilihat pada tabel ini.

Tabel 4. Uji Reliabilitas

\begin{tabular}{ccc}
\hline Variabel & $\begin{array}{c}\text { Hasil } \\
\text { Cronbach Alpha }\end{array}$ & Keterangan \\
\hline $\begin{array}{c}\text { Supervisi Kepala } \\
\text { Sekolah }\end{array}$ & 0.909 & Realibel \\
$\begin{array}{c}\text { Pengembangan } \\
\text { Tenaga Pendidik } \\
\text { Kinerja Guru }\end{array}$ & 0.828 & Realibel \\
\hline
\end{tabular}

Ini menunjukkan bahwa sampel yang diteliti, nilai Cronbach Alpha lebih besar dari 0.60, di mana Cronbach Alfa pada variabael supervisi Kepala Sekolah berjumlah 0,909. Pengembangan tenaga pendidik memiliki cronbach Alfa 0.828, sedangkan kinerja guru memiliki cronbach Alfa 0.961. Hal ini menunjukkan bahwa semua indikator dan variabel dinyatakan valid dan reliable.

Tabel 5. Kolmogorov-Smirnov

\begin{tabular}{|c|c|c|}
\hline \multirow[t]{2}{*}{ Variabel } & \multicolumn{2}{|c|}{$\begin{array}{l}\text { Kolmogorov- } \\
\text { Smirnova }^{\mathrm{a}}\end{array}$} \\
\hline & Statistic & Sig. \\
\hline $\begin{array}{l}\text { TOTAL_X1 (Supervisi Kepala } \\
\text { Sekolah) }\end{array}$ & .085 & $.200^{*}$ \\
\hline $\begin{array}{l}\text { TOTAL_X2 (Pengembangan } \\
\text { Tenaga Pendidik) }\end{array}$ & .097 & $.200^{*}$ \\
\hline TOTAL_Y (Kinerja Guru) & .114 & .051 \\
\hline
\end{tabular}

Dari hasil analisis variabel supervisi kepala sekolah $\left(\mathrm{X}_{1}\right)$ nilai signifikannya sebesar 0, 200, sedangkan signifikan variabel pengembangan tenaga pendidik $\left(\mathrm{X}_{2}\right)$ adalah 0,200 . Sementara variabel kinerja (Y) dengan signifkan 0,51. Artinya semua variabel memiliki nilai signifikan lebih besar dari alfa 0.05. Hal ini dapat disimpulkan bahwa semua data pada masing-masing variabel terdistribusi dengan normal.

Temuan penelitian bertentangan dengan hasil penelitian Sugiono \& Rahadhini (2011) yang meneliti Pengaruh Pendidikan dan Pelatihan, Motivasi Kerja, dan Lingkungan Kerja Terhadap Kinerja Guru SD Neferi Gabus Kabupaten Grobongan. Hasil penelitiannya tidak mendukung 
hipotesis bahwa pendidikan dan pelatihan tidak ada pengaruh yang signifikan terhadap kinerja guru SD Negeri di Kecamatan Gabus Kabupaten Grobongan. Jadi $\mathrm{H}_{1}$ tidak signifikan dengan kinerja guru. Sedangkan Tehreem et.al (2013) meneliti The Impact of employees on training on job performance in education sector of Pakistan. Desain penelitian menggunakan deskriptif dengan metode survey, sedangkan penelitian ini menggunakan metode kuantitatif dengan desain kautsal. Hasil penelitiannya menunjukkan hubungan yang signifikan antara banyak variabel pelatihan terhadap kinerja, bervariasi sebesar $40 \%$. Artinya $\mathrm{H}_{2}$ signifikan terhadap kinerja guru atau karyawan. Hakam, dkk (2013) juga meneliti tentang pengaruh pendidikan dan pelatihan terhadap kinerja karyawan, Jenis penelitiannya adalah explanatori, analisis data menggunakan analisis regresi linier berganda. Hasil penelitiannya menunjukkan pendidikan karyawan berpengaruh signifikan terhadap kinerja karyawan Joint Operating Body Pertamina-PetroChina East Java, $\mathrm{t}_{\text {hitung }}$ $2,067>1,663$ sedangkan sig 0,043 < 0,05. H1 berpengaruh signifikan terhadap kinerja guru. Persamaan penelitian ini dengan penelitian Hakam sama sama- menggunakan analisis regresi linear berganda.

Di tempat lain Hendriana (2003) meneliti pengaruh kegiatan kelompok kerja guru dan latar belakang pendidikan terhadap kinerja guru Sekolah Dasar di lingkungan Dinas Pendidikan Kecamatan Subang Kabupaten Subang. Penelitiannya menggunakan metode korelasional dan ex post facto. Hasil penelitiannya menyimpulkan bahwa 1) terdapat hubungan yang positif dan signifikan antara Kegiatan kelompok Kerja Guru (KKG) terhadap kinerja guru sebesar 48.86\%; 2) tidak terdapat hubungan yang signifikan atara pendidikan dengan kinerja guru; dan 3) terdapat hubungan yang positif dan signifikan secara sendri maupun bersama sama antara kegiatan Kelompok Kerja Guru (KKG) dan latar belakang pendidikan dengan kinerja guru sebesar 50.7\%. Selanjutnya, Khan (2011) meneliti tentang Impact of Training and Development on Organizational Performance. Hasil penelitiannya melalui analisis kuisioner tingkat respon sebesar $83 \%$. Hasil tersebut membuktikan Training berpengaruh signifikan terhadap kinerja organisasi, hal ini dibuktikan dari tabel berada pada rentang 4-5 dan 3-4 nilai z-tes itu terletak di daerah kritis. Begitu juga pengembagan karyawan berpengaruh signifikan terhadap kinerja organisasi.

Sukoco dan Kunartinah (2010) juga meneliti dalam penelitiannya tentang pengaruh pendidikan dan pelatihan, 
pembelajaran organisasi terhadap kinerja dengan kompetensi sebagai mediasi. Penelitiannya dilakukan di SMP RSBI negeri di Semarang, penelitian ini dengan penelitian Sukoco dan Kunartinah sama-sama menggunakan analisis data dengan regresi linier berganda. Hasil penelitiannya menunjukkan pendidikan dan pelatihan berpengaruh positif dan signifikan terhadap kinerja guru didukung dengan nilai beta 0,280 pada signifikan $0,001 .<0,05$, artinya $\mathrm{H} 2$ berpengaruh signifikan terhadap kinerja guru. Perbedaan penelitian nya adalah tempat dan populasi.

\section{KESIMPULAN}

Berdasarkan hasil penelitian dengan pengujian SPSS dapat disimpulkan bahwa 1) dari tingkat pencapaian responden pada olahan data kuisioner tahun 2016 secara umum tingkat pencapaian rata-rata jawaban responden adalah $81,6 \%$. Atau dikategorikan baik, artinya secara umum dapat dikatakan bahwa kinerja guru MAs di Lima Puluh Kota tahun 2016 dari aspek perencanaan pembelajaran, pelaksanaan pembelajaran, membina hubungan, membimbing, melatih dan pengasuhan, serta melaksanakan penilaian, analisis dan perbaikan pengayaan dalam keadaan baik dibanding data awal tahun 2016, begitu juga dalam supervisi kepala sekolah; 2) secara umum tingkat pencapaian responden pada variabel supervisi kepala sekolah rata-rata jawaban responden mencapai $80,5 \%$, rata-rata ini dikategorikan ke dalam kategori baik. Pelaksanaan supervisi kepala sekolah ini dilihat dari indikator pengembangan kurikulum, observasi dan pengembangan profesi, sedangkan pada variabel pengembangan kurikulum tingkat pencapaian responden berada pada rentang cukup yaitu dengan rata-rata 69,82 , rata-rata ini lihat dari keseluruhan indikator pengembangan tenaga pendidik yaitu pendidikan, pelatihan, work shop, seminar dan KKG; 3) variabel supervisi kepala sekolah berpengaruh positif dan signifikan terhadap kinerja guru MAs di Lima Puluh Kota, Hal ini dapat dilihat dari nilai sig $0,023<0,05$ Hasil penelitian ini menunjukkan bahwa semakin tinggi pelaksanaan supervisi kepala sekolah MAs di Lima Puluh Kota dalam pelaksanaan supervisi pengembangan kurikulum, observasi dan pengembangan profesi maka akan semakin baik atau semakin meningkat kinerja guru tersebut; dan 4) variabel pengembangan tenaga pendidik tidak berpengaruh signifikan terhadap kinerja guru MAs di Lima Puluh Kota. Hal ini terlihat dari nilai signifikan $0,91>0,05$. Hasil penelitian ini menunjukkan bahwa tinggi rendahnya pengembangan tenaga pendidik tidak 
mempengaruhi kinerja guru MAs di Lima

Puluh Kota.

\section{DAFTAR PUSTAKA}

Daft, Richard L. (2003). Manajemen. Jakarta: Salemba Empat

Fattah. Nanang. (2000). Manajemen Berbasis Sekolah. Bandung: Andika.

Gaol Jimmy (2015). A to Z Human Caapital Manajemen Sumber Daya Manusia. Jakarta. PT.Gramedia.

Hakam.S.M, Sunuharyo. S.B, Ningrum. W. (2013). "Pengaruh Pendidikan Dan Pelatihan Terhadap Kinerja Karyawan. Studi Pada Karyawan Joint Operating Body PertaminaPertolChina East Java". Jurnal Administrasi Bisnis (JAB) Vol.6 No 2 Desember 2013

Iswanto Yun. (2012). Manajemen Sumber Daya Manusia. Tangerang: Universitas Terbuka.

Kazmi, F. S. Sahen, N. \& Jahangir. F. S. (2012). "In Service Training:A Contibutory Factor Influencing Teachers' Performance". International Jurnal of Academic in Progressive Education and Development. January 2012, Vol. 1, No. 1.

Kementrian Pendidikan dan Kebudayaan Badan Pengembangan Sumber Daya Manusia Pendidikan Dan Kebudayaan dan Penjaminan Mutu Pendiidikan Pusat Penembangan Tenaga Kepedidikan. (2012). Pedoman Penilaian Kinerja Kepala Sekolah/Madrasah. Jakarta: Kemdikbud.
Khan, A.M. Khan. A.F. Khan. G.A. (2011). "Impact of Training and Development on Organizational Performance". Global Jurnal Manajemen dan Bisnis Penelitian. Volume 11 Issue 7 Versi Juli 1.0.2011. ISSN: 0975-5853.

Mulyasa. (2009). Menjadi Kepala Sekolah Profesional. Bandung: Remaja Rosdakarya.

. (2012). Manajemen \& Kepemimpinan Kepala Sekolah. Jakarta. Bumi Aksara

Purwanto, M. Ngalim. (2002). Administrasi dan Supervisi Pendidikan. Bandung: Remaja Rosda Karya.

Sahertian, A. Piet. (2010). Konsep Dasar dan Teknik Supervisi Pendidikan. Jakarta. Bumi Aksara

(2010). Konsep Dasar \& Teknik Supervisi Pendidikan Dalam Rangka Pengembangan Sumber Daya Manusia. Jakarta: Rineka Cipta.

Sugiono dan Rahadhini MD. (2011). "Pengaruh Pendidikan dan Pelatihan, Motivasi Kerja, dan Lingkungan Kerja Terhadap Kinerja Guru SD Gabus Kabupaten". Jurnal Manajemen Sumber Daya Manusia Vol.5 No.1 Juni 2011:1-10).

Sukoco, F. dan Kunartinah. (2010). "Pengaruh Pendidikan dan Pelatihan, Pembelajaran Organisasi Terhadap Kinerja Dengan Kompetensi Sebagai Mediasi". Jurnal Bisnis dan Ekonomi (JBE), ISSN:1412-3126).

Supardi. (2014). Kinerja Guru. Jakarta: PT. Raja Grafindo Persada.

Wibowo. (2011). Manajemen Kerja. Jakarta: PT.Raja Grafindo Persada. 